\title{
Outcome of acute myeloid leukaemia in Nigeria: clinician's perspective
}

\author{
Ann Abiola Ogbenna ${ }^{1}$ iD, Olufemi Abiola Oyedeji ${ }^{2}$, Christiana Oluwakemi Famuyiwa ${ }^{3}$, Babajide Ayodeji Sopekan ${ }^{4}$, Obadiah Dapus Damulak $^{5}$, \\ Esere Bernice Akpatason ${ }^{6}$, Gbenga Olorunfemi ${ }^{7}$ (iD) and Kehinde Adekola ${ }^{8}$
}

\begin{abstract}
${ }^{1}$ Department of Haematology and Blood Transfusion, College of Medicine, University of Lagos/Lagos University Teaching Hospital, Idi-Araba, Lagos, PMB 12003, Nigeria

${ }^{2}$ Department of Haematology and Blood Transfusion, College of Medicine, University of Lagos, Lagos, Nigeria

${ }^{3}$ Department of Haematology and Blood Transfusion, General Hospital Gbagada, Lagos, Nigeria

${ }^{4}$ Department of Community Medicine and Primary Care, College of Medicine, University of Lagos

${ }^{5}$ Department of Haematology and Blood Transfusion, Faculty of Clinical Sciences, College of Health Sciences, University of Jos, Nigeria

${ }^{6}$ Department of Haematology, National Orthopaedic Hospital, Igbobi-Lagos, Nigeria

${ }^{7}$ Division of Epidemiology and Biostatistics, School of Public Health, University of Witwatersrand, Johannesburg, South Africa

${ }^{8} \mathrm{Hem}$-Onc Stem Cell Transplant Unit, Division of Hematology-Oncology, Northwestern Memorial Hospital, Northwestern University, Feinberg School of Medicine, 676 North St. Clair Street, Suite 850, IL 60611, Chicago, USA

ahttps://orcid.org/0000-0003-1441-2308

bhttps://orcid.org/0000-0001-6634-8550
\end{abstract}

\begin{abstract}
The outcome of acute myeloid leukaemia (AML) has remained a major concern even in developed countries. In resource poor countries, it is envisaged that the outcome will be far worse because of late presentations, lack of appropriate diagnostic facilities and supportive care. However, data to validate this is lacking and many of these countries lack an effective cancer registry. This study determined the clinician's perspective of the outcome of care of AML patients in Nigeria and their attitudes to the care of these patients. Structured self-administered questionnaire was used to assess the clinician's perception of outcomes of care, contributory factors and attitude to care of AML patients. Ninetyeight percent of clinicians reported that the outcome of care was suboptimal; $73.3 \%$ and $90.6 \%$ of the clinicians reported having less than $31 \%$ of AML patients surviving induction and post-induction therapies, respectively. Sixty-six-point one percent (66.1\%), 50\% and $62.7 \%$ of the clinicians have never used immunophenotyping, cytogenetic or molecular studies, respectively, in the management of AML patients under their care. Access to blood components other than Red cells was low; $23.3 \%$ had access to apheresis platelets and $55 \%$ to fresh frozen plasma. Forty-six percent of clinicians will either give half dose of chemotherapy or offer only supportive care. This reported early death rate is three times higher than that reported in developed countries with only $9 \%$ likely to survive the first year of induction compared to about $32.9 \%$ in Ontario. Approximately 28 units of pooled or apheresis derived platelet may be required in course of therapy but just $10 \%$ of clinicians have access to platelet apheresis. Lack of diagnostic facilities, blood components and clinicians' attitudes are contributing factors to the extremely poor outcomes of patients with AML in Nigeria.
\end{abstract}

Keywords: clinical outcome in AML, clinician perspective, cytogenetic and molecular monitoring, blood component in low-income countries

ecancer 2021, 15:1239; www.ecancer.org; DOI: https://doi.org/10.3332/ecancer.2021.1239
Correspondence to: Ann Abiola Ogbenna Email: annabiolas@yahoo.co.uk

ecancer 2021, 15:1239

https://doi.org/10.3332/ecancer.2021.1239

Published: 25/05/2021

Received: 14/01/2021

Publication costs for this article were supported by ecancer (UK Charity number 1176307).

Copyright: (c) the authors; licensee ecancermedicalscience. This is an Open Access article distributed under the terms of the Creative Commons Attribution License (http:// creativecommons.org/licenses/by/3.0), which permits unrestricted use, distribution, and reproduction in any medium, provided the original work is properly cited. 


\section{Background}

Acute myeloid leukaemia (AML) is a heterogeneous group of diseases, characterised by clonal proliferation of immature myeloid cells in the peripheral blood and bone marrow. It is often associated with bone marrow failure.

AML has a global incidence of 351,965 in 2012 with an age-standardised rate of 4.7 per 100,000, a 5-year prevalence of $1.5 \%$ and a Male:Female ratio of approximately 1:4 [1]. Its incidence appears to be on the increase in developed countries [2, 3].

The estimated prevalence of AML in Africa is 1\% [4]. Africa is expected to witness the highest increase in AML cases over the next 10 years [4]. National prevalence of AML in Nigeria is not available; however, studies report that AML accounts for between $19 \%$ and $24 \%$ of leukaemias that were managed in hospitals [5-8]. Although these cancers are relatively rare, they have a disproportionally large effect on overall cancer survival statistics. It is the most common type of leukaemia in adults, yet continues to have the lowest survival rate of all leukaemias $[9,10]$.

The lack of an effective cancer registry, national algorithms for AML reporting and electronic data management systems in Nigeria has made it almost impossible getting population-based data on prevalence and outcomes of patients with AML in the country. Reliable survival statistics are essential for the evaluation of cancer treatments and care.

Moreover, the management of AML in Nigeria is sub-optimal. For example, facilities for cytogenetic and molecular genetics evaluation are not routinely available in Nigeria and samples often must be sent out of the country for patients that can afford the high cost of analysis. Furthermore, blood components are not readily available for the supportive care of the patients. The absence of adequate supportive care specifically, availability of appropriate blood component may also lead to reluctance among haematologists to administer conventional chemotherapy at its full dose, further diminishing the possibility of cure. Likewise, novel drugs such as Midostaurin, Gemtuzumab Ozogamicin, and bone marrow transplant (BMT) facilities offering services to patients with leukaemia are absent. Few Nigerians can afford BMT services outside the country [11]. Arsenic trioxide and all-trans-retinoic acid, drugs used in the treatment of acute promyelocytic leukaemia are also not readily available in the country. Therefore, despite its ease of diagnosis and management, outcome is still poor because drugs must be sourced from outside the country leading to unnecessary delay and even when the drugs are now available, blood component support is still a major challenge. The aforementioned factors taken together mean that delivering best care for AML in Nigeria is impossible.

Aside from a study in 1982 by Williams et al [12] which reported that four out of eight children with AML had varying degree of short-lived remission, a systematic literature search of PubMed, Google scholar, African Journals online and African Index online did not reveal any study on survival outcomes of patients with AML in Nigeria. Few studies which reported survival outcomes in haematologic malignancies in Nigeria did not differentiate the leukaemias [13-15]. This absence of data may be a reflection of the weak record system and cancer registry for leukaemia in the nation. Hence, we aimed to determine the clinician's perspective and attitudes towards management of patients with AML, outcomes of their patients with AML and factors that affect these outcomes to draw attention to the possible sup-optimal level of care in the country.

\section{Materials and methods}

We conducted a comparative cross-sectional study among Nigerian haematologists and haematologists in Training who attended the 44th annual scientific conference of the Nigerian Society of Haematology and Blood Transfusion (NSHBT) held in Calabar, Cross River State, South-South Nigeria from 29 to 31 of August 2018. The respondent must practice and reside in Nigeria to be eligible for recruitment. Membership of NSHBT includes haematologists, haematologists in training, general practitioners, laboratory scientists, nurses and paediatricians who are interested in haematology or blood banking.

All participants at the NSHBT conference who were consultant haematologist or haematologist in training were approached at the conference venue to participate in the study. A structured self-administered questionnaire was given to consenting participants to obtain data. Respondent's demographic and occupational characteristics including age, sex, religion, place of practice, duration of practice and professional cadre were elicited. Opinion on outcome of care of patients with AML, factors affecting it and attitude of clinicians to the care of 
patients with AML was assessed using a Likert scale of one to five, which consisted of nine attitude statements. One was strongly disagreed, two was disagree, three was neutral, four agree and five was strongly agree. Positive attitudinal statements were scored five (for participants who strongly agreed) to one (for participants who strongly disagreed). The opposite of this scoring system was used for negative attitudinal statements. Responses were scored in such a way that the higher the score, the more positive the attitude towards care of patients with the leukaemia.

Analysis was conducted using SPSS version 21. Categorical data (such as gender of participants) were presented as frequency, percentages and charts. Continuous data (such as age or attitudinal score of participants) were presented as mean \pm standard or median and interquartile range. A reliability analysis of the questionnaire was carried out by comparing the 9-item scale of the clinician's attitude. Cronbach's alpha showed the questions to reach acceptable reliability, $(\alpha=0.709)$. Most items appeared to be worthy of retention, resulting in a decreased Cronbach's alpha if deleted. Item five, however, increased $\alpha$ to 0.801 and had a much lower mean, hence it was removed. Responses to negatively structured questions were recoded and attitudinal score was obtained.

Pearson's Chi square test was used to test for association between attitudes of the physicians and their self-reported survival rate of their patients. Mann-Whitney $U$ test was used to assess the relationship between continuous variables and reported survival of AML patients. Confidence interval was set at $95 \%$ and the level of statistical significance was set at $p<0.05$.

\section{Ethical consideration}

Ethical approval was obtained from the Health Research and Ethics Committee of the Lagos University Teaching Hospital (HREC Number: ADM/DCST/HREC/APP/2512) and permission was obtained from the Chairman local organising committee of the 2018 National Society Haematology and Blood transfusion conference. Informed consent was obtained from all participants, confidentiality and anonymity were ensured.

\section{Results}

A total of 65 haematologists/haematologists in training were recruited. More than half of the respondents were consultants $(n=39 / 64,60 \%)$ with a male to female ratio of $1: 1.7$. The majority of clinicians were from the South-south $(n=19,30.6 \%)$ and South-west $(n=29,46.8 \%)$ regions of the country. Nearly all $(n=59,90.8 \%)$ of the participating clinicians practice at Teaching Hospitals nation-wide. The median year of practice for consultants, senior registrars and junior registrars was 9, 5.5 and 2 years, respectively (Table 1).

Only $1.6 \%$, $(n=1 / 61)$ of the physicians reported the overall outcome of AML patients under their care to be good, with about $67 \%$ of the respondents reporting poor to very poor outcomes. Eight (14.5\%) haematologists had between $40 \%$ and $50 \%$ of patients surviving induction therapy while 2 (3.5\%) had $40 \%-50 \%$ surviving post-induction. The majority, $73.2 \%$ and $90.6 \%$ had less than $31 \%$ surviving induction and post-induction, respectively (Table 2 ).

Half of the participating clinicians diagnosed AML solely on morphology (Figure 1). More than $50 \%$ of clinicians in this study did not use any ancillary diagnostic tests such as flow cytometry, cytogenetics and molecular studies (Figure 2).

Data collected showed that $96 \%$ of clinicians had access to red cell concentrates, $61.7 \%$ had access to platelet concentrate, $55 \%$ to fresh frozen plasma, $10 \%$ to cryoprecipitate and $23.3 \%$ to platelet apheresis (Figure 3).

Forty-two (67.7\%) out of 62 clinicians were not comfortable managing AML patients and the reasons are outlined below (Table 3 ). For 26 (62\%) of these responders, lack of adequate supportive care was the major reason for not being comfortable managing AML patients.

There was no statistically significant association between the possibility of survival and the professional level of clinicians or the goal of care, place and duration of practice, neither was there a statistically significant association between the possibility of survival and access to blood component support (Table 4). However, a more detailed review of data from the three clinicians that reported five or more patients alive showed that two were from South-West Nigeria, and one was from South-East. The clinician with the highest number of AML patients alive 
(10) is a haematologist with 30 years of practice, who sees an average of eight AML patients per year, making a total of 180 and a survival rate of $5.5 \%(10 / 180)$. Of the two with five patients alive, one had practiced for 12 years seeing approximately 20 AML patients per year, and the other 9 years with about three AML patients per year. This gives an approximate survival rate of $2.0 \%$ and $18.5 \%$, respectively. The clinicians with the highest record of AML patients were from the north of Nigeria (30 patients/year for 19 years of practice; 15 pts/year for 17 years of practice) and neither had any surviving patients.

Nineteen (29.2\%) clinicians believed that no AML patient could survive if solely treated in Nigeria; 17 (26.2\%) of the clinicians will often give half the dose of chemotherapy because of limited supportive care; 14 (21.5\%) avoid treatment at all because of the belief that patient will die when chemotherapy is started while 13 (20\%) would offer only supportive care, i.e. without chemotherapy because of their perceived chance of survival (Figure 4).

The median attitude score was 2.75 (IQR: 2.375-3.125, range: 1.50-4.13).

Table 1. Demographic and clinical experience of respondents.

\begin{tabular}{|c|c|c|}
\hline & Frequency $(n=65)$ & Percentage (\%) \\
\hline \multicolumn{3}{|l|}{ Sex } \\
\hline Male & 41 & 63.1 \\
\hline Female & 24 & 36.9 \\
\hline \multicolumn{3}{|l|}{ Marital status } \\
\hline Single & 8 & 12.3 \\
\hline Married & 55 & 84.6 \\
\hline Widower & 2 & 3.1 \\
\hline \multicolumn{3}{|l|}{ Religion } \\
\hline Christianity & 48 & 73.8 \\
\hline Islam & 17 & 26.2 \\
\hline \multicolumn{3}{|c|}{ Geopolitical zone of practice } \\
\hline South south & 19 & 30.6 \\
\hline South west & 29 & 46.8 \\
\hline South central & 3 & 4.8 \\
\hline North central & 5 & 8.1 \\
\hline North east & 2 & 3.2 \\
\hline North west & 4 & 6.5 \\
\hline \multicolumn{3}{|c|}{ Professional level $(n=64)$} \\
\hline Consultant & 39 & 60.0 \\
\hline Senior registrar & 12 & 18.5 \\
\hline Junior registrar & 13 & 20.0 \\
\hline \multicolumn{3}{|l|}{ Place of practice } \\
\hline Teaching hospitals & 59 & 90.8 \\
\hline General hospitals & 5 & 7.7 \\
\hline Federal hospitals & 1 & 1.5 \\
\hline \multicolumn{3}{|c|}{ Years of experience in haematology practice (Median (interquartile range) } \\
\hline Consultant & $9.0(3.5-17.0)$ & \\
\hline Senior registrar & $5.0(3.5-7.0)$ & \\
\hline Junior registrar & $2.0(1.25-2.0)$ & \\
\hline
\end{tabular}


Table 2. Self-reported practice of management of AML by Nigerian physicians.

\begin{tabular}{|c|c|c|}
\hline & Frequency & Percentage \% \\
\hline Number of AML cases seen per year by clinicians (Median, IQR) & $4(\mathrm{IQR}=5)$ years & \\
\hline Clinicians who were comfortable with managing AML & 20 & 32.3 \\
\hline \multicolumn{3}{|l|}{ Perceived outcome of AML patients treated by clinicians } \\
\hline Good & 1 & 1.6 \\
\hline Fair & 19 & 31.1 \\
\hline Poor & 23 & 37.7 \\
\hline Very poor & 18 & 29.5 \\
\hline \multicolumn{3}{|l|}{ Proportion of $A M L$ patients that survive induction } \\
\hline Nil & 10 & 17.9 \\
\hline$<10 \%$ & 15 & 26.8 \\
\hline $11 \%-20 \%$ & 12 & 21.4 \\
\hline $21 \%-30 \%$ & 4 & 7.1 \\
\hline $31 \%-40 \%$ & 7 & 12.5 \\
\hline $40 \%-50 \%$ & 8 & 14.3 \\
\hline Not sure & 8 & 12.5 \\
\hline \multicolumn{3}{|l|}{ Proportion of AML patients that survive post induction } \\
\hline Nil & 13 & 24.5 \\
\hline$<10 \%$ & 24 & 45.3 \\
\hline $11 \%-20 \%$ & 8 & 15.1 \\
\hline $21 \%-30 \%$ & 3 & 5.7 \\
\hline $31 \%-40 \%$ & 3 & 5.7 \\
\hline $40 \%-50 \%$ & 2 & 3.8 \\
\hline Not sure & 11 & 17.2 \\
\hline \multicolumn{3}{|l|}{ Has any of your AML patients benefited from BMT ${ }^{\mathrm{a}}$} \\
\hline Yes & 13 & 22.0 \\
\hline No & 46 & 78.0 \\
\hline \multicolumn{3}{|l|}{ What is your goal of care? } \\
\hline Cure & 32 & 54.2 \\
\hline Palliative & 27 & 45.8 \\
\hline Median number of patients with AML who had a BMT per clinician & \multicolumn{2}{|c|}{$1(\mathrm{IQR}=1, \mathrm{MIN}=1, \mathrm{MAX}=1)$} \\
\hline Median no of AML patients alive per clinician & 0 & \\
\hline
\end{tabular}

${ }^{\mathrm{a} B M T}$, Bone marrow transplant

\section{Discussion}

This study aimed at using the clinician's perspective of outcome of AML patients in their care as a surrogate marker for the chance of survival of patients with the leukaemia in Nigeria and to highlight the gross sub-optimal care of AML patients in Nigeria. The attitude of clinicians to the care of patients with AML patients was also evaluated. 


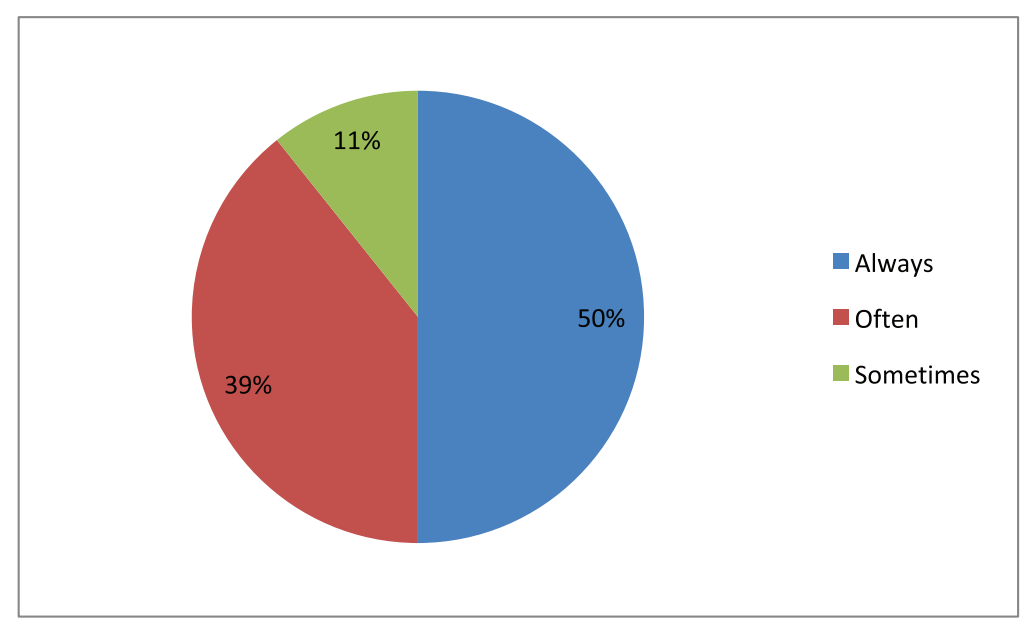

$N=64$

Figure 1. Frequency in which clinicians base the diagnosis of AML solely on morphology.

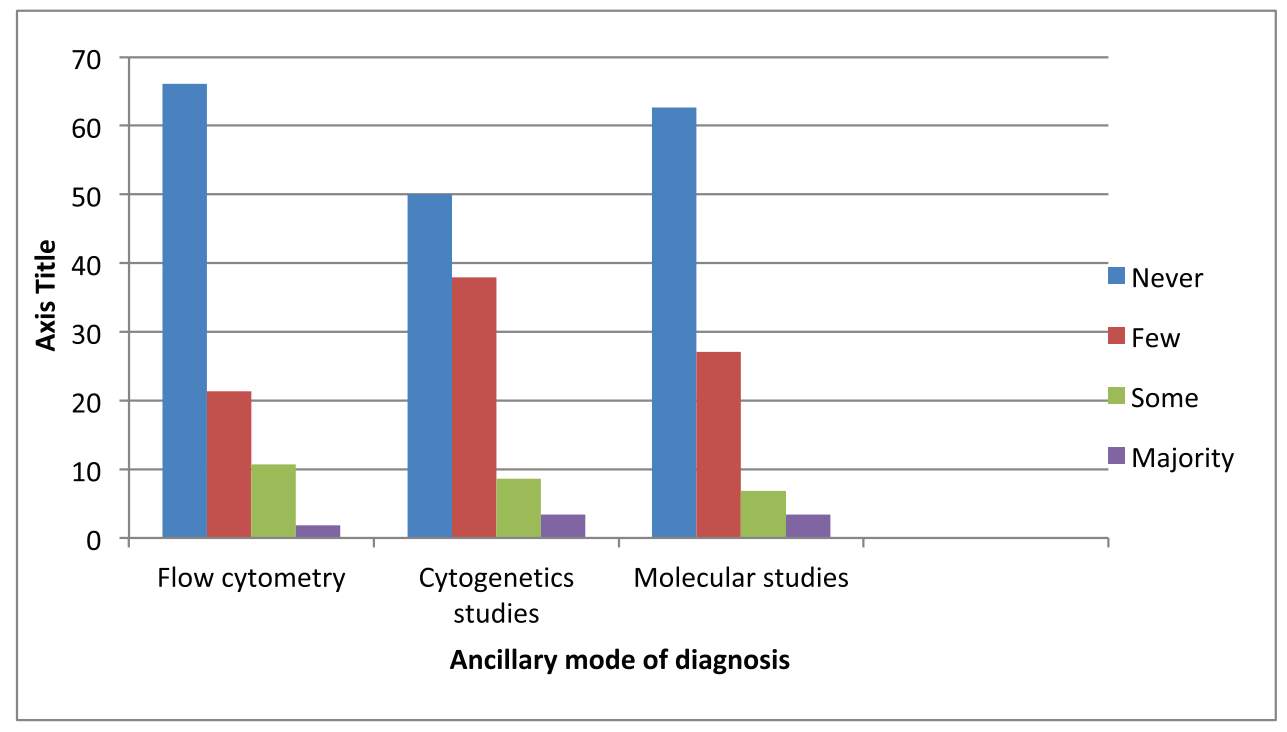

$N=65$

Figure 2. Frequency of ancillary mode of diagnosis used by clinicians in the management of AML.

Sixty-five haematologists participated in the study, $60 \%$ were consultant haematologists and others were residents in training. Median duration of practice for consultants was 9 years while senior registrars were 5 years.

The majority (67\%) of the participating clinicians reported that the outcome of patients with AML in Nigeria is poor or very poor. The United States, Surveillance, Epidemiology and End Result Cancer Statistics Review of 1975-2017 showed an improved 5-year survival of patients with AML from 1982 to 2013. In 2013, the overall 5-year survival rate was $27.4 \%$ compared to $10.6 \%$ in 1986 [16]. Thus, while high income countries are making strides towards reducing the fatality from AML, the situation in Nigeria does not suggest there have been any improvement in care. 


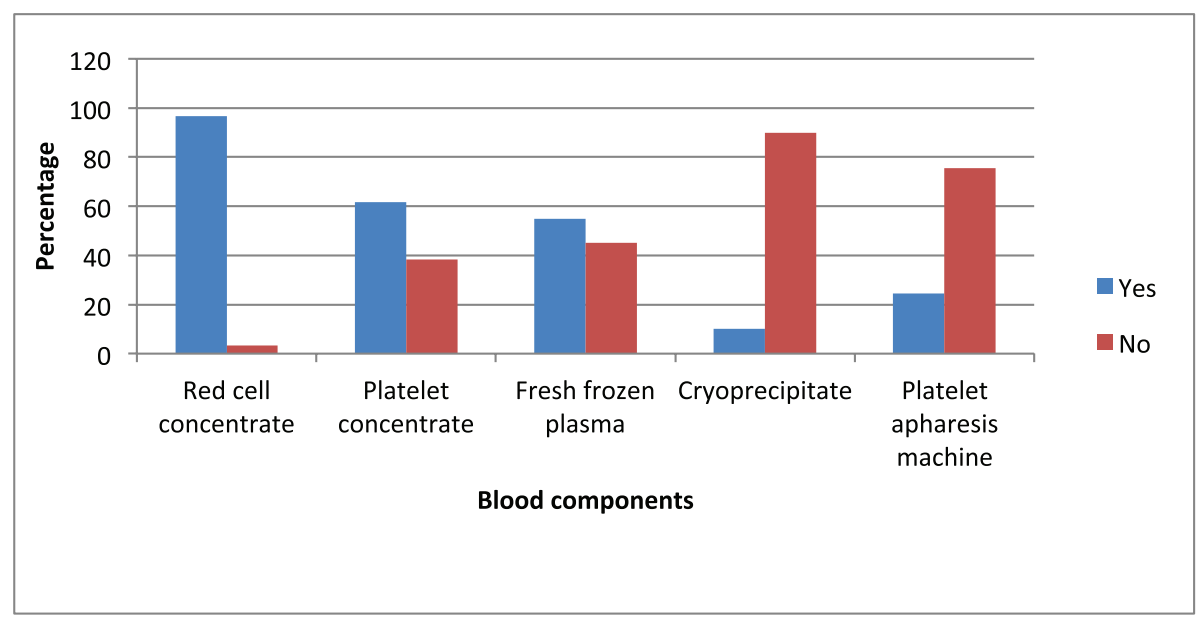

$N=65$

Figure 3. Bar chart showing proportion of clinicians with access to different blood components.

Table 3. Reasons why clinicians were not comfortable managing AML patients.

\begin{tabular}{|c|c|c|}
\hline & Frequency & Percentage \% \\
\hline \multicolumn{3}{|c|}{ High mortality } \\
\hline Yes & 12 & 28.6 \\
\hline No & 30 & 71.4 \\
\hline \multicolumn{3}{|c|}{ Late presentation } \\
\hline Yes & 2 & 4.8 \\
\hline No & 40 & 95.2 \\
\hline \multicolumn{3}{|c|}{ Lack of diagnostic facilities } \\
\hline Yes & 6 & 14.3 \\
\hline No & 36 & 85.7 \\
\hline \multicolumn{3}{|c|}{ Cost/financial constrain } \\
\hline Yes & 6 & 14.3 \\
\hline No & 36 & 85.7 \\
\hline \multicolumn{3}{|c|}{ Lack of standard/appropriate drug } \\
\hline Yes & 8 & 19.0 \\
\hline No & 34 & 81.0 \\
\hline \multicolumn{3}{|c|}{ Lack of adequate supportive care (blood component therapy) } \\
\hline Yes & 26 & 61.9 \\
\hline No & 16 & 38.1 \\
\hline
\end{tabular}


Table 4. Relationship between clinician-related and blood component factors and reported possibility of survival for AML patients.

\begin{tabular}{|c|c|c|c|}
\hline & None alive & Some alive & $p$-value \\
\hline \multicolumn{4}{|l|}{ Professional cadre } \\
\hline Consultant & 19 (54.3\%) & 19 (63.3\%) & $0.614^{a}$ \\
\hline Others & $16(45.7 \%)$ & $11(36.7 \%)$ & \\
\hline \multicolumn{4}{|l|}{ Goal of care } \\
\hline Cure & 17 (51.5\%) & $15(57.5 \%)$ & 0.793 \\
\hline Palliative & $10(48.5 \%)$ & $11(42.3 \%)$ & \\
\hline \multicolumn{4}{|l|}{ Place of practice } \\
\hline Teaching hospital & $31(88.6 \%)$ & $28(93.3 \%)$ & 0.275 \\
\hline General hospital & $4(11.4 \%)$ & $1(3.3 \%)$ & \\
\hline Federal medical centre & 0 & $1(3.3 \%)$ & \\
\hline \multicolumn{4}{|l|}{ Duration of practice } \\
\hline$\leq 10$ years & $28(80.0 \%)$ & $22(73.3 \%)$ & 0.567 \\
\hline$>10$ years & $7(20.0)$ & $8(26.7 \%)$ & \\
\hline Median duration of practice & 4.0 years $(2-10)$ & 5.5 years $(2-12)$ & $0.895^{b}$ \\
\hline \multicolumn{4}{|l|}{ Red cell concentrate } \\
\hline Yes & 32 (97.0\%) & $27(96.4 \%)$ & 0.906 \\
\hline No & $1(3.0 \%)$ & $1(3.6 \%)$ & \\
\hline \multicolumn{4}{|l|}{ Platelet concentrate } \\
\hline Yes & $20(60.6 \%)$ & $18(64.3 \%)$ & 0.768 \\
\hline No & $13(39.4 \%)$ & $10(35.7 \%)$ & \\
\hline \multicolumn{4}{|l|}{ Fresh frozen plasma } \\
\hline Yes & $16(48.5 \%)$ & $17(60.75)$ & 0.340 \\
\hline No & $17(51.5 \%)$ & $11(39.3 \%)$ & \\
\hline \multicolumn{4}{|l|}{ Cryoprecipitate } \\
\hline Yes & $3(9.1 \%)$ & $3(10.7 \%)$ & 0.832 \\
\hline No & 30 (90.9\%) & $25(89.3 \%)$ & \\
\hline \multicolumn{4}{|l|}{ Platelet apheresis machine } \\
\hline Yes & $7(20.6 \%)$ & $8(28.6 \%)$ & 0.388 \\
\hline No & 27 (79.4\%) & $19(67.9 \%)$ & \\
\hline \multicolumn{4}{|l|}{ BMT } \\
\hline Yes & $4(11.4 \%)$ & $5(18.5 \%)$ & 0.432 \\
\hline No & 31 (88.6\%) & $22(81.5 \%)$ & \\
\hline
\end{tabular}

${ }^{\mathrm{a}}$ Fishers exact test

bMann-Whitney test 
We found that about $64 \%$ of participating clinicians had $<30 \%$ of their AML patients surviving remission induction therapy. This can be translated to approximately $70 \%$ early death in AML patients in Nigeria. This is far higher than the overall $19 \%$ early deaths recorded from the Swedish Acute Leukemia Registry between 1997 and 2005 [17]. The reasons for this is multifactorial and can be broadly divided into patient based and treatment based. Often patients present late having been treated in several health facilities for malaria or 'typhoid'. Then when they do present, as seen in the attitude of clinicians to care (Figure 4), some would not be commenced on chemotherapy and those who do may have sub-optimal doses and when full doses are given, adequate blood component support is often lacking.

About three-quarters of the participating clinicians reported that less than $30 \%$ of AML patients that survived remission induction survived post induction therapy. In order words $70 \%$ of the $30 \%$ of patients who survived remission induction will die at post-induction chemotherapy. This implies that only $9 \%$ of AML patients survive therapy in the first year in contrast to about $32.9 \%$ first year survival reported by Alibhai et al in a 40-year study on outcomes of care amongst AML patients in Ontario. Thus, it is not surprising that the median number of AML patients said to be surviving by clinicians in Nigeria is zero. The chance of survival for AML patients in Nigeria is grave and there is need for this to be urgently addressed.

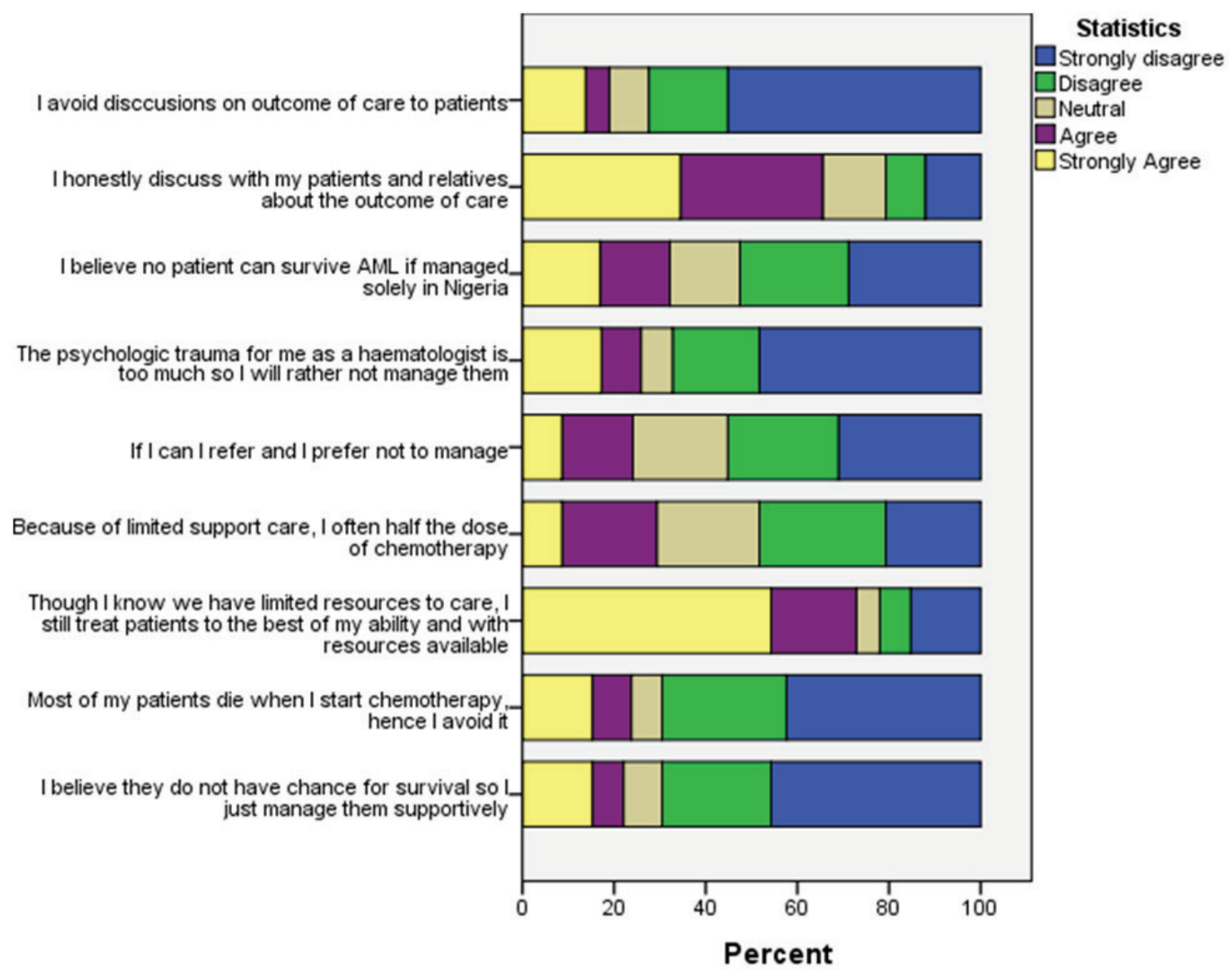

Figure 4. Frequency of response to Likert scale items assessing clinician's attitude to care of AML patients. 
Though the clinician with the highest number of AML patients per year (30/year) was from the north, it may not necessarily imply that there are more cases in the north, rather it may reflect the number of haematologist/per population. Table 1 shows that most of the haematologists were from the south. Despite this relatively higher number of patients per year, survival outcomes were worse (0\%). The three clinicians who had $\geq 5$ AML patients alive were from the south. This pattern mirrors the availability of blood products. Clinicians from the North West and North East reported they had neither platelet concentrates nor fresh frozen plasma. This may explain the 100\% mortality rate (Table 5).

Myelosuppression is a known cause of mortality in AML. Consequently, transfusion support is crucial to the care of patients from the beginning to the end of therapy [18]. However, there is little information on the exact units of transfusion requirements for these patients and the decision on how much to be transfused was solely dependent on the haematologists [19, 20]. Blood components such as platelet concentrates and cryoprecipitate are pooled from several donors. A single platelet dose is derived from approximately four to five donors hence substantial number of donors is needed to provide transfusion requirements to adequately support a single patient through induction and consolidation therapies [19].

A study by Dawson et al [19] in 2007 showed that approximately 150 donations were required to pool platelet for patient over the entire course of therapy. Another study carried out in 2015 recoded the median number of red blood cells (RBCs) and platelet transfused during induction therapy to be 12 RBC units (ranging from 0-49) and 10 platelet units (ranging from 0-62) [21]. This is a great challenge in Nigeria as few hospitals have readily available blood component facilities.

Only $10 \%$ of clinicians managing AML patients in Nigeria have access to platelet apheresis and almost $38 \%$ have no access to platelet concentrates. This is an issue that needs to be addressed to ensure better treatment outcome.

In spite of the advances in molecular diagnosis of AML, morphology of bone marrow cytology remains a diagnostic cornerstone [22, 23]. However, its use as a single diagnostic tool is prone to diagnostic inaccuracies [24]. Some form of AML (for example, AML-MO) cannot be diagnosed based on morphology alone as the blasts cells are large and agranular, resembling L2 cells in acute lymphoblastic leukaemia (ALL) [24]. Ancillary test such as cytochemistry, immunophenotyping, cytogenetic and molecular diagnostics are essential. Another limitation of morphology alone is reproducibility, thereby leading to poor diagnostic concordance. Study has shown that diagnosis of AML using morphology and other ancillary tests achieves an overall concordance rate of approximately 63\% [25]. Despite the aforementioned limitation, the French American British morphology classification remains the only step for the diagnosis and assessment of patients with AML in Nigeria. Our study further revealed that $66 \%$ of the clinicians had never used flow cytometry in the diagnosis or management of patients with AML, while about half of the respondents never used cytogenetics and $62.7 \%$ never used molecular studies. This will not permit for optimal patient care. It also infers that knowledge of these important tests amongst haematologists in Nigeria may be limited.

Table 5. Availability of blood component to clinicians in the six geo-political zones.

\begin{tabular}{|c|c|c|c|c|c|c|c|}
\hline & $\begin{array}{c}\text { S. East } \\
n(\%)\end{array}$ & $\begin{array}{c}\text { S. West } \\
n(\%)\end{array}$ & $\begin{array}{c}\text { S. South } \\
n(\%)\end{array}$ & $\begin{array}{c}\text { N. Central } \\
n(\%)\end{array}$ & $\begin{array}{c}\text { N. East } \\
n(\%)\end{array}$ & $\begin{array}{c}\text { N. West } \\
n(\%)\end{array}$ & $p$ value \\
\hline \multicolumn{8}{|c|}{ RBC concentrates } \\
\hline Yes & $2(3.4)$ & $29(50.0)$ & $18(31.0)$ & $3(5.2)$ & $2(3.4)$ & $4(6.9)$ & 0.382 \\
\hline No & $0(0.0)$ & $0(0.0)$ & $1(50.0)$ & $1(50.0)$ & $0(0.0)$ & $0(0.0)$ & \\
\hline \multicolumn{8}{|c|}{ Platelet concentrates } \\
\hline Yes & $2(5.5)$ & $25(67.6)$ & $7(18.9)$ & $3(8.1)$ & $0(0.0)$ & $0(0.0)$ & $<0.001$ \\
\hline No & $0(0.0)$ & $4(17.4)$ & $12(52.2)$ & $1(4.3)$ & $2(8.7)$ & $4(17.4)$ & \\
\hline \multicolumn{8}{|c|}{ Fresh frozen plasma } \\
\hline Yes & $1(3.1)$ & $24(75.0)$ & $4(12.5)$ & $2(6.5)$ & $1(3.1)$ & $0(0.0)$ & $<0.001$ \\
\hline No & $1(3.6)$ & 5 (17.9) & $15(53.6)$ & 2 (7.1) & $1(3.6)$ & 4 (14.3) & \\
\hline
\end{tabular}


Diagnostic karyotype and molecular genetics are key determinants in the clinical outcome of AML patients. They help to identify biologically distinct subsets of AML thus allowing for tailored and targeted therapeutic approach. They are also most valuable as prognostic determinant. They have become routine in the characterisation and care of patients with AML. Less than $50 \%$ of clinicians in this study use these tools. This will definitely limit the options of care and will negatively impact outcome of care [26].

Studies have shown that in the absence of allogeneic stem cell transplant, adults with AML offered intensive care who are $<60$ years have only a $16.6 \%$ chance of surviving for 10 years [27]. This further buttresses the importance of stem cell transplantation in the management of AML [27]. In this study, the median number of AML patients per clinician who had stem cell transplant was one. Also, ideally risk stratification of AML using the WHO 2016 criteria including cytogenetics and molecular tests described above helps the treating haematologist in determining patients that should be considered for stem cell transplantation.

Aside from performance status and co-morbidity, physician attitude also determines the choice of management of AML [28]. The general attitude of clinicians who take care of patients with AML in this study is Negative (median attitude score: 2.75, interquartile range (IQR) 2.4-3.1). Despite the poor attitude some clinicians, 43 (66.1\%) still treat AML patients with optimum care notwithstanding the limitations in the country.

The attitudes of clinicians in the choice of treatment are known to affect the quality of health care rendered and patient's outcome [29-33]. Study by Hui et al [34] showed that oncologists who have favourable attitude towards end of life care of their patients also provide primary palliative care.

This study is limited by recall bias, the inability to evaluate other determinants of survival like age at presentation and the fact that the selfreported values by the respondents are approximation [36, 37]. Despite these, our study still fills a void and provides valuable insight into the outcome of care of patients with AML in Nigeria. Further research should be carried out to assess the outcome of AML in Nigeria.

\section{Conclusion}

In conclusion, outcome of AML treatment in Nigeria is extremely poor. Lack of diagnostic facilities, blood components and clinicians' attitudes are contributing factors. We recommend improvement in the access to blood components and products via empowering and equipping the national and state transfusion services. We also recommend that the management of leukaemia be included in the National Health Insurance Scheme and anti-leukaemic drugs be added to the National health Insurance scheme medicine list. Finally, we recommend that a well-equipped national leukaemia centre be established where all resources (both diagnostic, therapeutic and clinical trials) for the optimal management of patients with leukaemia could be directed. This will also allow for data on leukaemias in the nation to be collated easily.

\section{Conflicts of interest}

We declare no conflict of interest.

\section{Acknowledgment}

Nil.

\section{Funding declaration}

This research was self-funded. 


\section{References}

1. Acute Myelogenous leukaemia and acute promyelocytic leukaemia (2014) Union for International Cancer Control 2014 Review of Cancer Medicines on the WHO List of Essential Medicines acute myelogenous leukemia (Including Acute Promyelocytic Leukemia) World Health Organization

2. Acute myeloid leukaemia (AML) incidence statistics|cancer research UK [Internet] London 2016 [https://www.cancerresearchuk.org/ health-professional/cancer-statistics/statistics-by-cancer-type/leukaemia-aml/incidence] Date accessed: 25/08/18

3. Australian cancer incidence and mortality (ACIM) books, ACIM books - Australian institute of health and welfare [Internet]. [https:// www.aihw.gov.au/reports/cancer/acim-books/contents/acim-books] Date accessed: 25/08/18

4. Hughes M (2017) The global incidence and prevalence of acute myeloid leukemia over the next ten years (2017-2027) J Cancer Res Ther [Internet] 13 pS50-S50 [https://web.a.ebscohost.com/abstract?direct=true\&profile=ehost\&scope=site\&authtype=crawler\&jrnl=0 9731482\&AN=127250837\&h=OsSiyKKWutruzKJeJE4GF2UsaH7TdDZ1dD5lvDhI2EeiYHykNa97QX57OHbrQmsaFp2Qvj\%2BcvGq1 QN9PracoKQ\%3D\%3D\&crl=c\&resultNs=AdminWebAuth\&resultLocal=] Date accessed: 25/08/18

5. Damulak O, Egesie O, and Jatau E, et al (2017) The pattern of leukaemias among adults in Jos, North Central Nigeria|Semantic scholar Ann Blood Res [Internet] 1(1) 1001 [https://www.semanticscholar.org/paper/The-Pattern-of-Leukaemias-among-Adults-in-Jos-\%2C/ e369b4814fdccb8ac25832905e3e8dcf0c13eb68] Date accessed: 18/05/20

6. Babatunde $A$, Amiwero $C$, and Olatunji $P$, et al (2008) Pattern of haematological malignancies in llorin, Nigeria: a ten year review Internet J Haematol [Internet] 5(2). [http://ispub.com/IJHE/5/2/13470] Date accessed: 25/08/18

7. Olaniyi J and Umar G (2013) An audit of acute leukaemias at the University College Hospital, Ibadan, Nigeria Open Acess Sci Rep 2(2) 649 Date accessed: 25/08/18 https://doi.org/10.4172/scientificreports.649

8. Omoti CE and Imiere EO (2006) Trends in the pattern of leukaemia incidence in a tertiary health center in Nigeria: 1990-2004 J Med Biomed Res [Internet] 5(2) 44-49 [http://www.bioline.org.br/request?jm06019] Date accessed: 18/05/20

9. Jemal A, Siegel R, and Ward E, et al (2018) Cancer statistics, 2006 CA Cancer J Clin [Internet] 56(2) 106-130 [http://www.ncbi.nlm.nih. gov/pubmed/16514137] Date accessed: 25/08/18 https://doi.org/10.3322/canjclin.56.2.106

10. Redaelli A, Lee JM, and Stephens JM, et al (2003) Epidemiology and clinical burden of acute myeloid leukemia Expert Rev Anticancer Ther 3(5) 695-710 https://doi.org/10.1586/14737140.3.5.695 PMID: 14599092

11. Uchechukwu NM, Oluwafemi A and Anthony N (2020) Cost and financial challenges of accessing bone marrow transplantation: opinion survey in a Nigerian tertiary institution Asian Hematol Res J [Internet] 3(2) 18-26 [https://www.journalahri.com/index.php/AHRJ/article/ view/30129] Date accessed: 15/03/21

12. Williams CKO, Folami AO, and Laditan AAO, et al (1982) Childhood acute leukaemia in a tropical population Br J Cancer [Internet] 46(1) 89-94 Date accessed: 29/05/21 https://doi.org/10.1038/bjc.1982.169

13. Egesie O, Agaba P, and Silas $O$, et al (2018) Presentation and survival in patients with hematologic malignancies in Jos, Nigeria: a retrospective cohort analysis J Med Trop [Internet] 20(1) 49 [http://www.jmedtropics.org/text.asp?2018/20/1/49/233428] Date accessed: 18/05/20 https://doi.org/10.4103/jomt.jomt_8_18

14. Allemani C, Matsuda T, and Di Carlo V, et al (2018) Global surveillance of trends in cancer survival 2000-14 (CONCORD-3): analysis of individual records for 37513025 patients diagnosed with one of 18 cancers from 322 population-based registries in 71 countries Lancet [Internet] 391(10125) 1023-1075 [https://linkinghub.elsevier.com/retrieve/pii/S0140673617333263] https://doi.org/10.1016/ S0140-6736(17)33326-3 PMCID: 5879496

15. Brown BJ, Bamgboye EA and Sodeinde O (2008) Early deaths and other challenges to childhood cancer survival in Ibadan, Nigeria Cent Afr J Med [Internet] 54(5-8) 32-39 [https://www.ajol.info/index.php/cajm/article/view/62625] Date accessed: 27/05/21 
16. Institute National Cancer (2020) Cancer statistics review, 1975-2017 - SEER statistics [Internet] eds N Howlader, A Noone, M Krapcho, and D Miller et al (Bethesda: National Cancer Institute) https://seer.cancer.gov/csr/1975_2017/ Date accessed: 18/05/20

17. Juliusson G, Lazarevic V, and Hörstedt AS, et al (2012) Acute myeloid leukemia in the real world: why population-based registries are needed Blood [Internet] 119(17) 3890-3899 [http://www.ncbi.nlm.nih.gov/pubmed/22383796] Date accessed: 15/05/19 https://doi. org/10.1182/blood-2011-12-379008 PMID: 22383796 PMCID: 3358248

18. Milligan DW, Grimwade D, and Cullis JO, et al (2006) Guidelines on the management of acute myeloid leukaemia in adults $\mathrm{Br} J \mathrm{Haematol}$ 135(4) 450-474 https://doi.org/10.1111/j.1365-2141.2006.06314.x PMID: 17054678

19. Dawson MA, Avery S, and McQuilten ZK, et al (2007) Blood transfusion requirements for patients undergoing chemotherapy for acute myeloid leukemia how much is enough? Haematologica 92(7) 996-997 https://doi.org/10.3324/haematol.11019 PMID: 17606456

20. Alwan A, Alrahal N and Alnuaimi MJ (2019) A one year anticipated blood transfusion requirements among patients with acute leukemia undergoing chemotherapy in the National Center of Hematology in Baghdad Iraqi J Hematol [Internet] 8(1) 25 [http://www.ijhonline.org/ text.asp?2019/8/1/25/252129] Date accessed: 18/05/20 https://doi.org/10.4103/ijh.ijh_12_18

21. Pleyer C, Afzal A, and Shomali W, et al (2015) Impact of red blood cell and platelet transfusions in acute myeloid leukemia (AML) patients undergoing remission induction chemotherapy Blood 126(23) 2127-2127 https://doi.org/10.1182/blood.V126.23.2127.2127

22. Döhner H, Estey E, and Grimwade D, et al (2017) Diagnosis and management of AML in adults: 2017 ELN recommendations from an international expert panel Blood 129(4) 424-447 https://doi.org/10.1182/blood-2016-08-733196 PMCID: 5291965

23. Orazi A (2007) Histopathology in the diagnosis and classification of acute myeloid leukemia, myelodysplastic syndromes, and myelodysplastic/myeloproliferative diseases Pathobiology 74(2) 97-114 https://doi.org/10.1159/000101709 PMID: 17587881

24. Bennett JM, Catovsky D, and Daniel MT, et al (1991) Proposal for the recognition of minimally differentiated acute myeloid leukaemia (AML-MO) BrJ Haematol 78(3) 325-329 https://doi.org/10.1111/j.1365-2141.1991.tb04444.x PMID: 1651754

25. Castoldi GL, Liso V, and Fenu S, et al (1993) Reproducibility of the morphological diagnostic criteria for acute myeloid leukemia: the GIMEMA group experience Ann Hematol 66(4) 171-174 https://doi.org/10.1007/BF01703231 PMID: 8485204

26. Grimwade D, Walker $\mathrm{H}$, and Oliver F, et al (1998) The importance of diagnostic cytogenetics on outcome in AML: analysis of 1,612 patients entered into the MRC AML 10 trial. The medical research council adult and children's leukaemia working parties Blood [Internet] 92(7) 2322-2333 [http://www.ncbi.nlm.nih.gov/pubmed/9746770] Date accessed: 18/05/20 https://doi.org/10.1182/blood. V92.7.2322

27. Vasu S, Kohlschmidt J, and Mrózek K, et al (2018) Ten-year outcome of patients with acute myeloid leukemia not treated with allogeneic transplantation in first complete remission Blood Adv 2(13) 1645-1650 https://doi.org/10.1182/bloodadvances.2017015222 PMID: 29991495 PMCID: 6039651

28. Eleni LD, Nicholas ZC and Alexandros S (2010) Challenges in treating older patients with acute myeloid leukemia J Oncol [Internet] 2010(11) 943823 [https://www.hindawi.com/journals/jo/2010/943823/] Date accessed: 18/05/20

29. Temel JS, Greer JA, and Muzikansky A, et al (2010) Early palliative care for patients with metastatic non-small-cell lung cancer $N$ Engl J Med 363(8) 733-742 https://doi.org/10.1056/NEJMoa1000678 PMID: 20818875

30. Zimmermann C, Swami N, and Krzyzanowska M, et al (2014) Early palliative care for patients with advanced cancer: a cluster-randomised controlled trial Lancet 383(9930) 1721-1730 https://doi.org/10.1016/S0140-6736(13)62416-2 PMID: 24559581

31. Burgess DJ, Fu SS and Van Ryn M (2004) Why do providers contribute to disparities and what can be done about it? J Gen Intern Med 19(11) 1154-1159 https://doi.org/10.1111/j.1525-1497.2004.30227.x PMID: 15566446 PMCID: 1494785 
32. Burgess DJ, van Ryn M, and Crowley-Matoka M, et al (2006) Understanding the provider contribution to race/ethnicity disparities in pain treatment: insights from dual process models of stereotyping Pain Med 7(2) 119-134 https://doi.org/10.1111/j.15264637.2006.00105.x PMID: $\underline{16634725}$

33. Institute of Medicine (US) Committee on Understanding and Eliminating Racial and Ethnic Disparities in Health Care (2003) Assessing potential sources of racial and ethnic disparities in care: the clinical encounter - unequal treatment - NCBI Bookshelf Unequal Treatment: Confronting Racial and Ethnic Disparities in Health Care [Internet] eds B Smedley, A Stith, and A Nelson (Washington: National Academies Press) [https://www.ncbi.nlm.nih.gov/books/NBK220340/\#ddd00134] Date accessed: 18/05/20

34. Hui D, Cerana MA, and Park M, et al (2016) Impact of oncologists' attitudes toward end-of-life care on patients' access to palliative care Oncologist 21(9) 1149-1155 https://doi.org/10.1634/theoncologist.2016-0090 PMID: 27412394 PMCID: 5016076

35. Mannava P, Durrant K, and Fisher J, et al (2015) Attitudes and behaviours of maternal health care providers in interactions with clients: a systematic review Global Health 11(1) 36. https://doi.org/10.1186/s12992-015-0117-9 PMID: 26276053 PMCID: 4537564

36. Appelbaum FR, Gundacker H, and Head DR, et al (2006) Age and acute myeloid leukemia Blood [Internet] 107(9) 3481-3485 [https:// ashpublications.org/blood/article/107/9/3481/133476/Age-and-acute-myeloid-leukemia] Date accessed: 18/05/20 https:/doi. org/10.1182/blood-2005-09-3724

37. Fröhling S, Schlenk RF, and Kayser S, et al (2006) Cytogenetics and age are major determinants of outcome in intensively treated acute myeloid leukemia patients older than 60 years: results from AMLSG trial AML HD98-B Blood [Internet] 108(10) 3280-3288 [https:// ashpublications.org/blood/article/108/10/3280/22756/Cytogenetics-and-age-are-major-determinants-of] https://doi.org/10.1182/ blood-2006-04-014324 